\title{
Imprinting disorders and assisted reproductive technology
}

\author{
Somjate Manipalviratn, M.D. ${ }^{a}$, Alan DeCherney, M.D. ${ }^{a}$, and James Segars, M.D. ${ }^{a}$ \\ ${ }^{a}$ Reproductive Biology and Medicine Branch, Eunice Kennedy Shriver National Institute of Child \\ Health and Human Development, National Institutes of Health, Bethesda, Maryland, USA
}

\begin{abstract}
Objective-To review currently available literature on the association between imprinting disorders (Beckwith-Wiedemann syndrome [BWS], Angleman syndrome [AS] and retinoblastoma) and assisted reproductive technologies (ART) in humans.
\end{abstract}

Design-Publications related to imprinting/epigenetic disorders including BWS, AS and retinoblastoma with ART and articles publishing outcome of ART, including IVF and ICSI, from July 1978 to February 2008 were identified using PubMed, Medline and EMBASE.

Result(s) -Considerable evidence in animal studies has demonstrated alteration in gene imprinting of embryos cultured in vitro. Publications from Europe, America and Australia have suggested an association between ART and BWS. Importantly, more than $90 \%$ of BWS in children born after ART had imprinting defects, compared to $40-50 \%$ of BWS in children conceived without ART. Moreover, there have been other reports suggesting an association between AS and ART. The majority of children with AS born after ART had an imprinting defect as the underlying etiology, specifically loss of methylation of the maternal allele. There was a single report suggesting an increased incidence of retinoblastoma in children conceived with ART.

Conclusion(s)-Because the absolute incidence of imprinting disorders is very small $(<$ 1:12,000 births), routine screening for imprinting disorders in children conceived with ART is not recommended. Additional large cohort studies of children born after ART are needed to determine whether there is a genuine association between ART and imprinting disorders.

\section{Keywords}

Imprinting disorders; epigenetic; Beckwith-Wiedemann syndrome; Angleman syndrome; retinoblastoma; assisted reproductive technology; IVF; ICSI

\section{Introduction}

In developed countries, 1-3\% of births involve some form of assisted reproductive technology (ART). Following a report by Cox, et al. in 2002 suggesting a link between Angleman syndrome (AS) in children conceived by intracytoplasmic sperm injection (ICSI) (1), there has been concern that imprinting disorders may be more prevalent in children born after ART. There is biologic plausibility for such concern because in the mouse model, embryo culture media has been shown to affect gene imprinting (2-4). To date, there are

\footnotetext{
Corresponding author: James Segars, M.D., Reproductive Biology and Medicine Branch, NICHD, NIH, Building 10, CRC, 1 East, Rm. 1-3140, 10 Center Drive, Bethesda, Maryland 20892, USA, Telephone: 301-496-5800, Fax: 301-402-0884, segarsj@mail.nih.gov.

Publisher's Disclaimer: This is a PDF file of an unedited manuscript that has been accepted for publication. As a service to our customers we are providing this early version of the manuscript. The manuscript will undergo copyediting, typesetting, and review of the resulting proof before it is published in its final citable form. Please note that during the production process errors may be discovered which could affect the content, and all legal disclaimers that apply to the journal pertain.
} 
quite a few publications from Europe, America and Australia suggesting an association between ART and Beckwith-Wiedemann syndrome (BWS), Angleman syndrome (AS) and retinoblastoma.

In this review, we summarize critical animal studies showing evidences of the effect of ovarian stimulation or embryo culture on gene imprinting. Next, we summarize current evidence of the association between imprinting disorders (BWS, AS and retinoblastoma) and the use of ART from July 1978, the time of birth of the first IVF baby, to February 2008. In addition, we reviewed the available registry of children born after ART for the incidence of imprinting disorders.

\section{Genomic Imprinting}

Diploid organisms possess two copies of each autosomal gene, one from each parent. Most autosomal genes are expressed simultaneously from both alleles; however, in a small subset of genes, one allele is silenced in a parent-specific manner by the process called "imprinting". Genomic imprinting is a process of chemical modification of nucleotides in which only one allele of specific genes is functioning and the other allele is silenced based on the parent-of-origin. The significance of gene imprinting was first shown in mouse nuclear-transplant studies (5-7). From these studies, mouse embryos generated by having either two female pronuclei (biparental gynogenones) or two male pronuclei (biparental androgenones) did not survive past mid-gestation. The androgenotes appeared to have retarded embryonic tissue development but well-developed extraembryonic tissue while gynogenotes appeared to have poorly-developed extraembryonic tissue with relatively normal, though small, embryos (6-9). From these studies, it was concluded that maternal and paternal genomes were non-equivalent in their contribution to normal embryogenesis.

There are currently more than 80 imprinted genes in mammals, of which about 40 genes are known to be imprinted in human (10). A comprehensive list of imprinted mammalian genes and parent-of-origin effect database can be found at www.otago.ac.nz/IGC (11). A majority of the imprinted genes play roles in the control of embryonic and placental growth and development. Abnormality in genomic imprints in human is known to cause 10 syndromes (Table 1).

\section{Mechanisms of Gene Imprinting}

Gene imprinting is an epigenetic process in which there is structural adaptation of chromosomal regions so as to register, signal or perpetuate altered activity states of specific genes without a change in nucleic acid sequence. Imprinting is a dynamic process which is erased and re-established according to the sex of the individual. DNA methylation and histone modifications are 2 major mechanisms for genetic imprinting in mammals, including humans.

$\mathrm{CpG}$ islands are genomic regions containing a high frequency of CG dinucleotides. $\mathrm{CpG}$ islands are in or near approximately $70 \%$ of promoters in human genes (12). DNA methylation generally occurs on the cytosine residues of cytosine-phosphate-guanine $(\mathrm{CpG})$ dinucleotides by the action of several DNA methyltransferase (DNMT). It was demonstrated in a murine model that mice deficient in DNA methyltransferase activity had altered expression of imprinted genes (13). It was suggested that maintenance and de novo methylation of DNA was under control of separate enzymes (14). DNMT1, a sequenceindependent methytransferase, has a preference toward the hemi-methylated substrate, and thus functions mainly to maintain methylation status of DNA during DNA replication resulting in a stable propagation of methylation pattern after each cell division (15). DNMT3A and DNMT3B have sequence-specific de novo methyltransferases that act at 
specific stages of gametogenesis and early development to establish a methylation pattern according to the parent-of-origin $(14,15)$. The regions with different methylation patterns in male and female gametes are called differentially methylated regions (DMRs). Approximately $80 \%$ of imprinted genes are physically linked in clusters with other imprinted genes (16). The grouping of imprinted genes within clusters allows them to share common DMRs and other common regulatory elements. The universal role of DNA methylation is transcriptional repression of the methylated gene sequences (17). DNA methylation therefore directly interferes with gene transcription by preventing the binding of basal transcriptional factors that require contact with cytosine in the major groove of the double helix (17). The other mechanism by which $\mathrm{CpG}$ methylation suppresses gene expression is by direct exclusion of transcriptional machinery from methylated promoter DNA (17). Also, CpG island chromatin is enriched in hyperacetylated histones and deficient in linker histones which are essential for transcriptional competency of genes. A family of proteins binding to methylated DNA (MBDs) has been identified and such proteins complex with histone deacetylases leading to local deacetylation of histone tails in methylated DNA forming a more condensed chromatin structure that is resistant to transcription (18). However, DNA methylation can silence certain genes (H19) and activate other genes (IGF2, $I G F 2 R)$ (13). The $H 19$ and IGF2 genes are in close proximity within an imprinted gene cluster and are mechanically linked through a common set of transcriptional regulatory elements (19). The $H 19$ gene encodes a maternally expressed, un-translated RNA while $I G F 2$ gene encodes paternally expressed growth factor. In the absence of methylation of the maternal DMR upstream of $H 19$, a chromatin insulator protein called CTCF binds to this DMR sequence altering chromatin structure of the maternal allele such that enhancer elements are available to $H 19$ but not to $I G F 2(20,21)$. In contrast, CTCF does not bind to the methylated DMR of paternal $H 19$ allele changing the chromatin configuration in that the enhancer can only up-regulate the expression of IGF2 but not $H 19$ (21).

Histones are the major protein components of chromatin acting as a core around which DNA bound. Specifically, each nucleosome consists of 147 base-pairs of DNA wrapped around an octamer of four core histone proteins (22). Histone proteins are subject to a large number of convalent modifications such as methylation, acetylation, ubiquitylation and phosphorylation. These modifications can induce either gene activation or suppression depending on the nature of modification and the specific amino acid modified (23-26). Histone modifications influence gene expression by changing either the chromatin structural configuration or interactions between factors that regulate gene expression and chromatin (22).

\section{Cycle of Gene Imprinting}

Gene imprinting is a dynamic process established during germ cell proliferation, migration, and development and is modified after fertilization. The imprinting marks are maintained after fertilization and propagate through each cell division for the entire life of the creature including humans.

Germ cells have the ability to erase the imprinting marks during their development in embryonic life. During the erasure process, there is marked and genome-wide demethylation in germ cells which is completed by embryonic day 12-13 in both male and female mice $(16,27,28)$. The erasure of methylation imprints has been demonstrated at 12.5-13.5 days post-coitum (dpc) in the mice germ line, one day after the primordial germ cells reach the gonadal ridge $(29,30)$. After the erasure of the imprinting marks, differentiating germ cells re-establish a de novo imprinting marks according to their sex. The re-establishment process begins in germ lines of both sexes at late fetal stages and continues after birth (27). In female germ cells (oocytes), reestablishment of imprinting occurs during their growth and is not completed until just before ovulation in each ovulatory cycle over the reproductive life 
span of the female $(31,32)$. Unlike female germ cells, male germ cells undergo complete reestablishment of paternal imprinting marks earlier in the process of gametogenesis, by the round spermatid stage (33). In mouse model, remethylation begins before birth $(18.5 \mathrm{dpc})$ in both male and female mice but is not complete until after birth $(29,34)$. The final de novo methylation is presumably completed during the final maturation phase in the epididymis for sperm, and just prior to or even after ovulation for oocytes $(29,34)$. As oocytes do not complete the re-methylation process until just before (or after) ovulation, assisted reproductive technology (ART), which generally involves stimulation of oocyte growth and retrieval of oocytes directly from the ovary prior to ovulation, could theoretically disrupt the imprinting process in oocytes. Unlike oocytes, sperms complete their imprinting process earlier in their development in the epididymis so ART is unlikely to affect imprinting defect in sperms $(35,36)$.

After fertilization, early embryos undergo a genome-wide demethylation process in which the hypo-methylated stage is retained through the blastocyst stage (29). However, the differential methylation marks of imprinted genes are protected from this global demethylation process resulting in the transgenerational inheritance of epigenetic states of imprinted genes $(37,38)$.

Due to the very limited material, and ethical restrictions for the study of human primordial germ cells, knowledge in genetic expression and imprinting patterns are inferred from the pattern in the mouse model. In the human, primordial germ cells are formed in the epiblast during week 2 of development, migrate from the yolk sac toward the gonadal ridge on week 4 and arrive the gonadal ridge at the end of week $5(35,39)$. Female germ cells enter meiosis by 10 weeks and remain arrested in the diplotene stage of meiosis I until just before ovulation while male germ cells continue mitosis until 16-18 weeks of gestation and then arrest in mitosis before entering meiosis postnatally (35).

\section{How ART might affect gene imprinting?}

ART involves manipulation of many steps of conception from the stimulation of gamete production to the ex vivo culture of embryos. These manipulations include: the use of hormones to down-regulate pituitary function and to stimulate ovary for supernumerary oocyte production, in vitro maturation of oocytes, the use of immature sperm, the use of intracytoplasmic sperm injection (ICSI) with direct injection of sperm, the in vitro culture of pre-implantation embryos before transferring back to the uterus, and cryopreservation of either gametes or embryos. Any of these steps of ART might alter the normal imprinting process.

Though the effect of ART on gene imprinting in humans is not well studied due to ethical considerations, there are quite a few animal model studies suggesting that ART may have an impact on gene imprinting. A well-known phenotype of cattle born after in vitro cultured of embryos is large offspring syndrome (LOS). LOS is characterized by unusually high birthweight, neonatal respiratory distress, organ overgrowth, skeletal anomalies, and an increased incidence of neonatal sudden death (40). Large offspring syndrome was associated with reduced fetal methylation and expression of $I G F 2 R$ which could be produced in sheep by culturing the embryos in vitro with co-culture granulosa cells and/or serum (41). A recent study of mouse 2-cell embryos showed that methylation level of in vitro developed embryos was significantly higher than those cultivated in vivo (2). In the same study, the authors also demonstrated a higher degree of demethylation of male pronuclei after fertilization in the in vivo cultivated embryos compared to the in vitro cultured embryos while methylation status of female pronuclei was not different between groups (2). This finding supports the hypothesis that an altered embryonic genome expression of in vitro cultured embryos could be the result of epigenetic modification (42). Embryo culture media also has been shown to 
effect imprinting status of some imprinted genes. A study of mouse embryos demonstrated differential expression and imprinting status of an imprinted gene, H19, when cultured in 2 different culture medias, having a loss in methylation of H19 in embryos cultured in Whitten's medium but not in embryos cultured in KSOM+AA medium (3). However, the DNA methyltransferase activity and the distribution of DNMT1 protein were similar between embryos of both groups (3). A subsequent study of mouse embryos also showed a different degree of expression of growth-related imprinted genes including H19, IGF2, GRB10 and GRB7 between embryos cultured in vivo, ex vivo in M16 media and ex vivo in M16 media plus fetal calf serum (4). From these findings, it is clear that culture media could alter gene expression and imprinting, though the degree of sensitivity of an imprinted gene to the culture environment appears to vary depending upon the gene $(3,4)$.

The possible mechanisms by which embryo culture conditions affect imprinting include: i) failure of transitory movement of Dnmtlo into the nucleus at the right stage of embryo development in in vitro culture embryos (38); ii) altered expression of the various DNMTs of other proteins involved in establishment and maintenance of imprint (38); iii) alteration in cell cycle kinetics in the in vitro cultured embryos interfering with epigenetic reprogramming $(38,43)$; and iv) removal or interaction of methyl group on DNA or on histone tails with culture media (43).

Recently, a well-designed study evaluated the impact of ovulation (superovulation versus non-superovulation), fertilization process (in vivo versus in vitro), embryo culture process (in vivo versus in vitro) and type of culture media (M16 medium versus G1.2/G2.2 sequential medium) on the methylation status of $H 19$ Imprinting Control Region (ICR) and proximal promoter of $H 19$ (PP) in mouse embryos (44). The investigators showed that epigenetic alteration of $H 19$ ICR and H19 PP were influenced by the fertilization method. The methylation defect was only seen in the in vitro fertilized subgroup and the degree of abnormality varied according to type of culture medium, being more common in M16 compared to G1.2/G2.2 medium (44). Moreover, superovulation was shown to clearly disrupt $\mathrm{H} 19$ gene expression in blastocysts but the degree of disruption of $\mathrm{H} 19$ gene expression also depended on type of culture media (44). This study supported a prior finding that in vitro fertilized mouse embryos have higher incidence of aberrant imprinting of the IGF2/H19 imprinted gene than in vivo fertilized mouse embryos (9/23 versus 1/14) (45).

Hormonal stimulation of the ovary is a common practice at ART to obtain multiple oocytes for fertilization and improve pregnancy success. The higher incidence of an abnormal methylation pattern in 2-cell embryos collected from superovulated female mice compared to non-superovulated mice suggests an adverse effect of hormonal stimulation on gene imprinting (46). Again, recent studies suggested hormonal stimulation of the ovary altered imprinting status of some genes in the human. There was a loss of PEG1 methylation and a gain of $H 19$ methylation in superovulated immature human oocytes (47). Nevertheless, the normal methylation status in mature human oocytes was not examined in this study. However, in this same study, the researchers demonstrated DNA methylation of the normally unmethylated H19 DMR in superovulated mouse oocytes was similar to that seen in superovulated human oocytes, suggesting that the changes in human $H 19$ locus were due, at least in part, to the superovulation procedure (47). The effect of hormonal stimulation of the ovary on oocyte gene imprinting requires further study.

Currently, some investigators have proposed to use in vitro matured (IVM) oocytes to avoid aggressive stimulation of the ovaries and thus life-threatening ovarian hyperstimulation syndrome. As maternal imprint is re-established during oocyte growth and maturation, IVM of oocytes may therefore interfere with imprint acquisition and/or maintenance. Data from a bovine study demonstrated that there was a significant alteration in DNA methylation in 
liver and muscle of bovine fetuses conceived with the use of IVM oocytes (48). The alteration in DNA methylation varied with the IVM protocols. ${ }^{47}$ Moreover, liver hypermethylation was associated with fetal overgrowth and endocrine changes (48). In human, the majority of MI-arrested oocytes exhibited an altered pattern of methylation (49). 15 of 20 IVM MII-human oocytes exhibited the normal unmethylated maternal patterns, while the other 5 exhibited an abnormal methylated pattern of the IGF2/H19 DMR (49). Though the number of human oocytes analyzed in this report was small, the study highlights the need for further research. However, the susceptibility of other genes such as $K v D M R l$ to imprinting defect during IVM may be different as the majority of oocytes had maternal methylation imprints of $K v D M R l$ established from the germinal vesicle stage (50).

Men with a suboptimal sperm count/quality can conceive with the use of intracytoplasmic sperm injection (ICSI). Without the use of ICSI, these men would remain infertile. A study on $H 19$ methylation pattern in sperm suggested an association between abnormal genomic imprinting and hypospermatogenesis (51). It was shown that 0,17 and $30 \%$ of men with normozoospermia, moderate oligozoospermia and severe oligozoospermia had altered $H 19$ methylation profile, respectively (51). This finding was supported by another study showing $14 \%$ and $20 \%$ of infertile men had abnormal paternal and maternal methylation imprints in their sperm, respectively (52). However, there was no evidence that the use of immature sperm for fertilization could cause an imprinting defect because normal imprinting in spermatogenesis was completed very early in the developmental process of spermatogonia (36).

Recent publication demonstrated that even minimal embryo manipulations involving blastocyst collection and embryo transfer using in vivo generated blastocysts cultured in vitro for less than 1.5 hours were associated with loss of methylation on the maternal allele of $K v D M R 1$ locus and consequently causing bi-allelic expression of KCNQ1OTI in mouse extra-embryonic tissue (53). Moreover, in vitro culture of embryos from 2-cell stage to blastocyst further exacerbated this aberration by increasing the number of genes with aberrant allelic expression and involve both embryonic and extra-embryonic tissue (53).

Most of the studies of imprinting defects examined DNA methylation; there is scant evidence of an effect of ART on histone modification. A study examining the histone modification status in murine embryos from zygote to blastocyst stage found no difference in the histone modification patterns between in vivo and in vitro fertilized mouse embryos though the histone modification patterns differed in different stages of development (54).

\section{Current evidence for a relationship between imprinting disorders and ART in humans}

Beckwith-Wiedemann Syndrome-Beckwith-Wiedemann Syndrome (BWS) is a rare imprinting disorder with an estimated incidence of 1 in 13,700 live births (55). BWS is a congenital overgrowth syndrome characterized by macroglossia, midline abdominal wall defects, macrosomia, neonatal hypoglycemia and a number of other developmental anomalies (56). Moreover, BWS children have an increased risk of developing embryonal tumors such as Wilm's tumor, rhabdomyosarcoma and hepatoblastoma (57). BWS is a multigenic disorder. BWS and its related tumors result from dysregulation of several closely linked genes associated with cell cycle and growth control on chromosome 11p15 (58). Imprinted genes implicated in the etiology of BWS map to the $11 \mathrm{p} 15$ imprinted region including the paternally expressed genes $I G F 2$ and $K C N Q 1 O T 1$, and the maternally expressed genes H19, CDKNIC and KCNQ1 (Figure 1) (58). Normally, the H19 and IGF2 genes are coordinately regulated by DMR 1 so that $H 19$ is only expressed from the maternal allele whereas IGF2 is only expressed from the paternal allele. The molecular basis of BWS cases are shown in Table 2. The largest molecular subgroups of BWS (>50\%) have imprinting defect on chromosome 11p15 (59). Earlier findings showed an increased 
incidence of monozygotic twins among children born with BWS with the majority of cases being discordant for BWS and having imprinting defect at $K C N Q 1 O T 1$ on $11 \mathrm{p} 15(60,61)$. From these earlier findings, it was suggested that an alteration in imprinting process might be due to the differential vulnerability to the loss of an imprinting event at a critical stage during pre-implantation development, a stage generally manipulated during the process of ART.

There were 3 case series reported in 2003 from BWS registries in Europe and America that suggested an association between ART and BWS (62-64). In 2003, DeBaun et al. reported 7 cases of BWS offspring born after the use of ART (2 IVF and 5 ICSI) (62). Six of the seven children were tested for the molecular basis of their BWS. Five of the six children tested had abnormal imprinting of the LITI (also known as KCNQ1OT1) and/or $H 19$ genes (62). In order to ascertain the prevalence of ART in their BWS cohort, they excluded data before 2001 in which data on ART utilization was not systematically collected. The authors reported the ART prevalence rate of $4.6 \%$ (3 of 65) in their BWS cohort compared to $0.76 \%$ prevalence rate of ART in general population in the United States in 1999 (62). Another review of 149 sporadic BWS cases in Birmingham, UK reported that 6 of 149 children with BWS (4\%) were born with the use of ART ( 3 after ICSI and 3 after conventional IVF) which was significantly higher than $1.2 \%$ ART utilization rates in general population (63). In this study, all 4 children tested for uniparental disomy were negative (63). In 2 children assessed for KvDMRl methylation, both showed loss of methylation on the maternal allele. Another series of 149 BWS cases in France had 6 children born after ART (64). All 6 children exhibited the same epigenetic abnormality having hypomethylation of $K v D M R I$ with a demethylation index varying from $72-100 \%$ (64). In this series, the prevalence of ART was $4 \%$ in BWS cohort compared to $1.3 \%$ in general French population during that time (64). The odds ratio of the exposure to ART and having BWS is 3.2 (95\% CI 1.4-7.3) (64).

A well-designed case-control study was performed in the State of Victoria, Australia from data between 1983 and 2003 (65). For each BWS case, 4 live-born controls were randomly selected from babies born within 1 month of the index case, in which parity was 1 and the maternal age was within 1 year of the risk-set case (65). There were 37 cases of BWS and 148 non-BWS matched controls. In this study, the overall prevalence of BWS was $1 / 35,580$ live births while the prevalence of BWS was $\sim 1 / 4,000$ among children born after ART (65). There were $4(10.81 \%)$ and $1(0.67 \%)$ children conceived with the use of ART in the BWS and non-BWS control group, respectively, giving an odds ratio of 17.8 (95\% CI 1.8 - 432.9) (65). All 3 BWS children born after ART tested for KvDMRI/LIT1 methylation had loss of methylation at this imprinted region compared to only $46 \%$ of BWS children born without the use of ART (65).

In 2005, Chang et al. identified 19 children born after ART in their registry comprised of 341 BWS patients (66). The authors reviewed the laboratory data of 12 patients for whom information on reproductive treatment was available. Ten children were born after ART (5 IVF and 5 ICSI) (66). The other 2 children were born after ovarian stimulation with intrauterine insemination (66). The investigators did not observe any common type of in vitro culture media or day of embryo transfer among children with BWS (66). The only common features among the 12 children were ovarian stimulation medication (11 gonadotropin, 1 clomiphine citrate) (66).

Another survey in the United Kingdom comprised of 213 families who had a child with BWS received 83 responses (39\% response rate) to a questionnaire about fertility treatments (67). Among the responders, 79 sporadic BWS cases were included in the analysis while the other 4 familial BWS cases were excluded. Six of 79 children with BWS conceived with the 
use of ART (1 IVF, 5 ICSI). The authors reported a 2.9\% ART prevalence (using the number of questionnaires sent excluding familial BWS cases as denominator, $\mathrm{N}=209$ ) among BWS children which was significantly higher than $0.8 \%$ in the general UK population during the same period (67). If the authors had used only the responders as the denominator, the ART prevalence would have been as high as 7.6\% (6/79). All cases of BWS conceived after ART involved loss of maternal methylation at the KvDMRl imprint control region, compared to the expected $50 \%$ chance of having this molecular alteration as the etiology of BWS in this population (67).

A large cohort study from Denmark included all Danish singletons born from January 1, 1995 to December 31, 2001 recorded in the National IVF Registry and National Birth Registry and comprised 442,349 non-IVF and 6,052 IVF singletons (68). Among 6,052 IVF children, 1,680 (28\%) and 4,372 (72\%) children were conceived with ICSI and without ICSI, respectively. The mean follow-up times were 4.5 and 4.1 years for non-IVF and IVF cohorts, respectively. This study was designed to assess the incidence of imprinting diseases in children born after IVF and that of naturally conceived children. There were no cases of BWS identified in both IVF and non-IVF cohort (68). In this study, an increased risk of the overall imprinting diseases after IVF was not observed (68).

Another large population-based study from Sweden during the period of 1982-2001 evaluated the presence of congenital malformation based on data from the Swedish Medical Birth Register, the Swedish Registry of Congenital Malformations, and the Swedish Hospital Discharge Register. There were no cases of BWS identified among 16,280 children born after ART (69).

A questionnaire-based cohort study of children conceived with ART from 2 study centers in the United Kingdom was recently published (70). Of the total 2,492 screening questionnaires distributed to all children born after ART between 1989 and 2003, the response rate was $61 \%$ corresponding to data from 1,524 children (70). The questionnaire was developed by experts in BWS and Angelman syndrome (AS) with an aim to detect children with possible diagnosis of BWS or AS. Of 70 children identified by the questionnaire as possibly warranting further clinical assessment, 47 (67\%) accepted the invitation for further evaluation to confirm the diagnosis. One case of BWS was identified in this cohort of 1,524 children born after ART having hypomethylation at KvDMRI as the underlying molecular mechanism (70). Data from this study suggested that prevalence of BWS in children born after ART $(1$ in 1,524) is higher than generally quoted $(1$ in 13,700) in normal live births. However, the absolute risk of having a child with BWS from ART was notably remote $(<0.1 \%)$.

Another nation-wide questionnaire survey in the Netherlands examined the use of ART among children with imprinting disorders born from January 1983 until December 2003. The authors reported no increased incidence of ART related birth of BWS, AS and PWS children after a correction was made for infertility in parents (71). However, if the subpopulation of 71 cases of BWS is considered, 4 children were born with the use of IVF or ICSI resulting in a prevalence of ART among these children of 5.6\% (relative risk $=6.1$ ) which is significantly higher than $0.92 \%$ in general Dutch population during the same period of time (71). All 4 cases of IVF-born BWS children tested for molecular etiology had hypomethylation at $\operatorname{LITl}(71)$.

The 7 case-series/case control/survey studies among children with BWS (Table 3), consistently reported a higher prevalence of ART $(59,62-65,67,70,71)$. In contrast, the findings from cohort studies were inconsistent, 2 of the 3 cohort studies $(68,69)$ failed to detect any cases of BWS among children born after ART while a third study (70) reported a 
significantly higher prevalence of BWS among ART-born children (Table 4). A large cooperative international study will be required to compare the prevalence of BWS among naturally conceived children and children born after ART. Moreover, as the majority of individuals with BWS do well both physically and developmentally (59), the prevalence of BWS may be underestimated in general population compared to the children born after ART which are usually scrutinized for their health and development, especially in cases with mild degree of clinical presentation. It is concerning that all reports have consistently demonstrated that $90-100 \%$ of cases had an imprinting aberration, mainly hypomethylation of maternal allele, as the molecular cause in BWS cases born after ART compared to the generally reported rates of $50-60 \%$ in general BWS population $(62-67,71)$. However, the increased rate of imprinting abnormality among BWS cases born after the use of ART could be due to chance and/or bias as not all cases of BWS in each report were evaluated for their molecular causes. Though current evidence has suggested an association between BWS and ART, routine screening of BWS in these children is not warranted as the overall prevalence of BWS in these children is considered too infrequent to justify screening $(1: 4,000)(65)$.

Angleman Syndrome-Angleman syndrome (AS) is a rare neurogenetic disorder characterized by severe mental retardation, seizures, frequent smiling and laughter and abnormal gait (72). The molecular cause of AS is a deficiency of maternal gene expression of the $U B E 3 A$ gene, located within the imprinting cluster at chromosome $15 \mathrm{q} 11$ to $15 \mathrm{q} 13$, in the brain (Figure 2) $(72,73)$. Loss of maternal gene expression of the UBE3A gene can result from a deletion, a mutation, a paternal uniparental disomy, or an imprinting defect of the maternal allelles. The prevalence of AS was estimated at 1:12,000 in general population (74); however, imprinting abnormalities are the etiology responsible for AS in less than 5\% of all cases, accounting for $\sim 1: 300,000$ newborns (1).

The first publication to suggest an association between AS and ICSI reported 2 children with AS born after the use of ICSI indicated by male infertility (1). Both children had significant hypomethylation of chromosome $15 \mathrm{q} 11$ to $15 \mathrm{q} 13$ analyzed by Southern blotting using a SNRPN probe (1). This report raised alarm for an association between imprinting disorders and ART because the incidence of AS due to an imprinting defect is extremely rare in general population $(\sim 1: 300,000)$.

Another publication in the following year reported a third case of AS in a girl conceived after ICSI (75). The molecular analysis revealed normal chromosome 15 of biparental origin with a complete absence of a methylated maternal pattern for the SNRPN locus. However, this girl had an intact AS imprinting center (IC). Unlike the other 2 girls in the earlier study (1) whose fathers had male infertility, this girl was born to a father who had normal sperm but had a mother and maternal grandmother with a history of reproductive difficulties, discounting the possibility that the imprinting defect could be related to male infertility (75).

A third recent study demonstrated that $20 \%$ of AS patients were born to subfertile couples (76). Among 16 AS cases born to a subfertile couple with or without infertility treatment, 4 cases (25\%) had an imprinting defect (76). Three children were born after ICSI and one of these children had an imprinting defect (76). Assuming that an imprinting defect accounts for $4 \%$ of AS patients, the relative risk of imprinting defect in AS children born to couples with subfertility was 6.25 (95\% CI 1.68-16.00) and the relative risk of imprinting defect in AS children born to untreated couples with subfertility was identical to that of those treated by ICSI or by hormonal stimulation alone ( $\mathrm{RR}=6.25$; 95\% CI, 0.70-22.57) (76). The relative risk was twice as high in subfertile couples who had received treatment $(\mathrm{RR}=2.5 ; 95 \% \mathrm{CI}$, 1.40-45.13) (76). Data from this study suggested that subfertile couples had an increased risk of conceiving a child with an imprinting defect causing AS. The authors also suggested that imprinting defects and subfertility may have a common cause, and that superovulation 
rather than ICSI may further increase the risk of conceiving a child with an imprinting defect (76).

A British survey of 384 families with a child with AS had found that among 75 responders with sporadic AS, 3 children were born after assisted conception. However, only one child was born with the use of IVF and this child appeared to have imprinting abnormality (67). The other 2 cases were conceived with the use of artificial insemination using donor sperm (67). Assuming there were no more cases of assisted conception in the non-responders, this would indicate a minimum of $0.26 \%$ IVF births among these children.

A nation-wide survey in the Netherlands recently reported that 12 of 63 AS children (19\%) were born to families with fertility problems compared to $5.6 \%$ of children born to families with fertility problem in general Dutch population during the same period $(\mathrm{RR}=3.4, \mathrm{p}<$ $0.001)$ (71). Three children (4.8\%) were born with the use of ovulation induction medication compared to $0.39 \%$ among Dutch population $(\mathrm{RR}=12.3$, $\mathrm{p}<0.001)(71)$. However, no children with AS were born with the use of IVF/ICSI (71). The data from this study suggested that a higher percentage of AS children were born to parents with fertility problems who used ovulation induction medication. This information supported the earlier study of Ludwig et al (76).

In the most recent survey of 2,492 children born after ART in the United Kingdom among 1,524 responders, there were no cases of AS reported (70). Nevertheless, as the incidence of AS caused by imprinting defects in this population was estimated at $\sim 1: 750,000$, this small study cohort may not have detected a 50-fold increased risk (70).

A small prospective study analyzed DNA-methylation patterns at chromosome 15q11-q13 in 92 children born after ICSI and showed a normal methylation pattern in all children (77). However, as the incidence of AS caused by imprinting defect is very rare $(\sim 1: 300,000)$, the number of children analyzed in this study was too small to detect an increased prevalence of imprinting abnormalities of AS among children born after ICSI.

To date, there are 7 reported cases of AS born after IVF or ICSI and 5 of these children appeared to have imprinting defect as the etiology (Table 5) $(1,67,75,76)$. Though the number of cases are small due to the rarity of disease, the proportion of children with imprinting defect as a cause of AS, 71\% (5/7), is higher than in general population suggesting an association between ART and AS. It remains unclear whether IVF/ICSI or ovulation induction is the cause of this imprinting defect and further study is needed.

Retinoblastoma-Retinoblastoma is a childhood malignant tumor of retina with an incidence of $\sim 1$ per 17,000 livebirth (78). Retinoblastoma is commonly caused by mutation of one allele of the tumor suppressor gene $R B 1$ combined with chromosomal loss or deletion of the other allele (38). However, hypermethylation of $R B$ gene that inactivates its tumor suppressor function was demonstrated to play a role in the development of retinoblastoma $(79,80)$. There was an alarming report from the Netherlands of 5 children with retinoblastoma, conceived between November 2000 and February 2002 by ART, suggesting a significant increased risk of 4.9-7.2 (81). Among these 5 children, one patient had a mutation as the etiology of retinoblastoma. However, in that report, the imprinting status of $R B$ gene was not evaluated. There have been no subsequent publications to suggest an association between retinoblastoma and ART. A large cohort study from Denmark including all Danish singleton born from January 1, 1995 to December 31, 2001 using National IVF Registry and National Birth Registry reported no cases of retinoblastoma among 6,052 IVF singleton with the mean follow-up time of 4.1 years (68). 


\section{Conclusion}

Several case reports, case series and cohort studies have suggested an association of ART usage with offspring born with imprinting disorders, mainly BWS and AS. There is biologic plausibility for concern because embryo manipulations and ovarian stimulations associated with ART have clearly been shown to cause imprinting disorders in animals. Moreover, the proportion of BWS and AS caused by imprinting defects in children born after ART is much higher than those conceived naturally, supporting the notion that ART might cause the imprinting disorders. As the incidence of imprinting disorders is very rare, conclusions from the current literature are tempered by limitations in study design. Though limited by study design and sample sizes, case series/case-control studies from different populations all suggested an association between BWS and ART, specifically hypomethylation of maternal allele. AS caused by sporadic imprinting defects is very rare, therefore 5 cases of these children born after ART may be cause for concern.

Large prospective, multi-center, cohort, studies are needed to assess growth and development of children born after ART in order to definitively answer the question of whether ART may cause an increased prevalence of imprinting disorders. Moreover, whether underlying infertility etiology, ovulation induction or IVF/ICSI procedure is the true cause for the increased prevalence of imprinting disorders with ART remains to be determined.

\section{Acknowledgments}

Support: This work was supported (in part) by the Intramural Research Program of the NICHD/NIH.

\section{References}

1. Cox GF, Burger J, Lip V, Mau UA, Sperling K, Wu BL, et al. Intracytoplasmic sperm injection may increase the risk of imprinting defects. Am J Hum Genet. 2002; 71:162-4. [PubMed: 12016591]

2. Zaitseva I, Zaitsev S, Alenina N, Bader M, Krivokharchenko A. Dynamics of DNA-demethylation in early mouse and rat embryos developed in vivo and in vitro. Mol Reprod Dev. 2007; 74:1255-61. [PubMed: 17290422]

3. Doherty AS, Mann MR, Tremblay KD, Bartolomei MS, Schultz RM. Differential effects of culture on imprinted H19 expression in the preimplantation mouse embryo. Biol Reprod. 2000; 62:152635. [PubMed: 10819752]

4. Khosla S, Dean W, Brown D, Reik W, Feil R. Culture of preimplantation mouse embryos affects fetal development and the expression of imprinted gene. Biol Reprod. 2001; 64:918-26. [PubMed: 11207209]

5. McGrath J, Solter D. Completion of mouse embryogenesis requires both the maternal and paternal genomes. Cell. 1984; 37:179-183. [PubMed: 6722870]

6. Barton SC, Surani MA, Norris ML. Role of paternal and maternal genomes in mouse development. Nature. 1984; 311:374-6. [PubMed: 6482961]

7. Surani MA, Barton SC, Norris ML. Development of reconstituted mouse eggs suggested imprinting of the genome during gametogenesis. Nature. 1984; 308:548-50. [PubMed: 6709062]

8. Surani MA, Barton SC. Development of gynogenetic eggs in the mouse -implications for parthenogenetic embryos. Science. 1983; 222:1034-6. [PubMed: 6648518]

9. Barton SC, Adams CA, Norris ML, Surani MA. Development of gynogentic and parthenogenetic inner cell mass and trophectoderm tissues in reconstituted blastocysts in the mouse. J Embryol Exp Morphol. 1985; 90:267-85. [PubMed: 3834032]

10. Morison IM, Ramsay JP, Spencer HG. A census of mammalian imprinting. Trends Genet. 2005; 21:457-65. [PubMed: 15990197] 
11. Glaser RL, Ramsay JP, Morison IM. The imprinted gene and parent-of-origin effect database now includes parental origin of de novo mutations. Nucleic Acids Res. 2006; 34 (Database issue):D2931. [PubMed: 16381868]

12. Saxonov S, Berg P, Brutlag DL. A genome-wide analysis of $\mathrm{CpG}$ dinucleotides in the human genome distinguishes two distinct classes of promoters. Proc Natl Acad Sci USA. 2006; 103:1412-7. [PubMed: 16432200]

13. Li E, Beard C, Jaenisch R. Role for DNA methylation in genomic imprinting. Nature. 1993; 366:362-5. [PubMed: 8247133]

14. Okano M, Bell DW, Haber DA, Li E. DNA methyltransferases Dnmt3a and Dnmt3b are essential for de novo methylation and mammalian development. Cell. 1999; 99:247-57. [PubMed: 10555141]

15. Bestor TH. The DNA methyltransferases of mammals. Hum Mol Genet. 2000; 9:2395-402. [PubMed: 11005794]

16. Reik W, Walter J. Genomic imprinting: parental influence on the genome. Nat Rev Genet. 2001; 2:21-32. [PubMed: 11253064]

17. Bird AP, Wolffe AP. Methylation-induced repression-belts, braces, and chromatin. Cell. 1999; 99:451-4. [PubMed: 10589672]

18. Reik W, Dean W. DNA methylation and mammalian epigenetics. Electrophoresis. 2001; 22:283843. [PubMed: 11565778]

19. Leighton PA, Saam JR, Ingram RS, Stewart CL, Tilghman SM. An enhancer deletion affects both H19 and Igf2 expression. Genes Dev. 1995; 9:2079-89. [PubMed: 7544754]

20. Bell AC, Felsenfeld G. Methylation of a CTCF-dependent boundary controls imprinted expression of the Igf2 gene. Nature. 2000; 405:482-5. [PubMed: 10839546]

21. Hark AT, Schoenherr CJ, Katz DJ, Ingram RS, Levorse JM, Tilghman SM. CTCF mediates methylation-sensitive enhancer-blocking activity at the H19/Igf2 locus. Nature. 2000; 405:486-9. [PubMed: 10839547]

22. Martin C, Zhang Y. Mechanisms of epigenetic inheritance. Curr Opin Cell Biol. 2007; 19:266-72. [PubMed: 17466502]

23. Zhang Y. Transcriptional regulation by histone ubiquitination and deubiquitination. Genes Dev. 2003; 17:2733-40. [PubMed: 14630937]

24. Martin C, Zhang Y. The diverse functions of histone lysine methylation. Nat Rev Mol Cell Biol. 2005; 6:838-49. [PubMed: 16261189]

25. Thiriet C, Hayes JJ. Chromatin in need of a fix: phosphorylation of H2AX connects chromatin to DNA repair. Mol Cell. 2005; 18:617-22. [PubMed: 15949437]

26. Margueron R, Trojer P, Reinberg D. The key to development: interpreting the histone code? Curr Opin Genet Dev. 2005; 15:163-76. [PubMed: 15797199]

27. Brandeis M, Kafri T, Ariel M, Chaillet JR, McCarrey J, Razin A, et al. The ontogeny of allelespecific methylation associated with imprinted genes in the mouse. EMBO J. 1993; 12:3669-77. [PubMed: 7504628]

28. Tada T, Tada M, Hilton K, Barton SC, Sado T, Takagi N, et al. Epigenotype switching of imprintable loci in embryonic germ cells. Dev Genes Evol. 1998; 207:551-61. [PubMed: 9510550]

29. Kafri T, Ariel M, Brandeis M, Shemer R, Urven L, McCarrey J, et al. Developmental pattern of gene-specific DNA methylation in the mouse embryo and germ line. Genes Dev. 1992; 6:705-14. [PubMed: 1577268]

30. Hajkova P, Erhardt S, Lane N, Haaf T, El-Maarri O, Reik W, et al. Epigenetic reprogramming in mouse primordial germ cells. Mech Dev. 2002; 117:15-23. [PubMed: 12204247]

31. Schaefer CB, Ooi SKT, Bestor TH, Bourc'his D. Epigenetic decisions in mammalian germ cells. Science. 2007; 316:398-9. [PubMed: 17446388]

32. Obata Y, Kaneko-Ishino T, Koide T, Takai Y, Ueda T, Domeki I, et al. Disruption of primary imprinting during oocyte growth leads to the modified expression of imprinted genes during embryogenesis. Development. 1998; 125:1553-60. [PubMed: 9502736] 
33. Shamanski FL, Kimura Y, Lavoir MC, Pedersen RA, Yanagimachi R. Status of genomic imprinting in mouse spermatids. Hum Reprod. 1999; 14:1050-6. [PubMed: 10221240]

34. Imamura T, Kerjean A, Heams T, Kupiec JJ, Thenevin C, Paldi A. Dynamic CpG and non-CpG methylation of the Peg1/Mest gene in the mouse oocytes and preimplantation embryo. J Biol Chem. 2005; 280:20171-5. [PubMed: 15778220]

35. Allegrucci C, Thurston A, Lucas E, Young L. Epigenetics and the germline. Reproduction. 2005; 129:137-49. [PubMed: 15695608]

36. Hartmann S, Bergmann M, Bohle RM, Weidner W, Steger K. Genetic imprinting during impaired spermatogenesis. Mol Hum Reprod. 2006; 12:407-11. [PubMed: 16608903]

37. Lane N, Dean W, Erhardt S, Hajkova P, Surani A, Walter J, et al. Resistance of IAPs to methylation reprogramming may provide a mechanism for epigenetic inheritance in the mouse. Genesis. 2003; 35:88-93. [PubMed: 12533790]

38. Thompson JR, Williams CJ. Genomic imprinting and assisted reproductive technology: connections and potential risks. Semin Reprod Med. 2005; 23:285-95. [PubMed: 16059835]

39. Sadler, TW. Langman's medical Embryology. Baltimore, USA: Lippincott, Williams and Wilkins; 2004.

40. Young LE, Sinclair KD, Wilmut I. Large offspring syndrome in cattle and sheep. Rev Reprod. 1998; 3:155-63. [PubMed: 9829550]

41. Young LE, Fernandes K, McEvoy TG, Butterwith SC, Gutierrez CG, Carolan C, et al. Epigenetic change in IGF2R is associated with fetal overgrowth after sheep embryo culture. Nat Genet. 2001; 27:153-4. [PubMed: 11175780]

42. Niemann H, Wrenzycki C. Alteration of expression of developmentally important genes in preimplantation bovine embryos by in vitro culture conditions: implication for subsequent development. Theriogenology. 2000; 53:21-34. [PubMed: 10735059]

43. De Rycke M, Liebaers I, Van Steirteghem A. Epigenetic risks related to assisted reproductive technologies: risk analysis and epigenetic inheritance. Hum Reprod. 2002; 17:2487-94. [PubMed: 12351517]

44. Fauque P, Jouannet P, Lesaffre C, Ripoche MA, Dandolo L, Vaiman D, et al. Assisted reproductive technology affects development kinetics, H19 imprinting control region methylation and H19 gene expression in individual mouse embryos. BMC Dev Biol. 2007; 18:116. [PubMed: 17949482]

45. Li T, Vu TH, Ulaner GA, Littman E, Ling JQ, Chen HL, et al. IVF results in de novo DNA methylation and histone methylation at an Igf2-H19 imprinting epigenetic switch. Mol Hum Reprod. 2005; 11:631-40. [PubMed: 16219628]

46. Shi W, Haaf T. Aberrant methylation patterns at the two-cell stage as an indicator of early developmental failure. Mol Reprod Dev. 2002; 63:329-34. [PubMed: 12237948]

47. Sato A, Otsu E, Negishi H, Utsunomiya T, Arima T. Aberration DNA methylation of imprinted loci in superovulated oocytes. Hum Reprod. 2007; 22:26-35. [PubMed: 16923747]

48. Hiendleder S, Wirtz M, Mund C, Klempt M, Reichenbach HD, Stojkovic M, et al. Tissue-specific effects of in vitro fertilization procedures on genomic cytosine methylation levels in overgrown and normal sized bovine fetuses. Biol Reprod. 2006; 75:17-23. [PubMed: 16554415]

49. Borghol N, Lornage J, Blachere T, Garret AS, Lefevre A. Epigenetic status of the H19 locus in human oocytes following in vitro maturation. Genomic. 2006; 87:417-26.

50. Geuns E, Hilven P, Van Steirteghem A, Liebaers I, De Rycke M. Methylation analysis of KvDMR1 in human oocytes. J Med Genet. 2007; 44:144-7. [PubMed: 16950814]

51. Marques CJ, Carvalho F, Sousa M, Barros A. Genomic imprinting in disruptive spermatogenesis. Lancet. 2004; 363:1700-2. [PubMed: 15158633]

52. Kobayashi H, Sato a, Otsu E. Aberrant DNA methylation of imprinted loci in sperm from oligospermic patients. Hum Mol Genet. 2007; 16:2542-51. [PubMed: 17636251]

53. Rivera RM, Stein P, Weaver JR, Mager J, Schultz RM, Bartolomei MS. Manipulations of mouse embryos prior to implantation result in aberrant expression of imprinted genes on day 9.5 of development. Hum Mol Genet. 2008; 17:1-14. [PubMed: 17901045] 
54. Huang JC, Lei ZL, Shi LH, Miao YL, Yang JW, Ouyang YC, et al. Comparison of histone modifications in in vivo and in vitro fertilization mouse embryos. Biochem Biophys Res Commun. 2007; 354:77-83. [PubMed: 17210126]

55. Thorburn MJ, Wright ES, Miller CG, Smith-Read EH. Exomphalos-macroglossia-gigantism syndrome in Jamaican infants. Am J Dis Child. 1970; 119:316-21. [PubMed: 5434588]

56. Elliott M, Bayly R, Cole T, Temple IK, Maher ER. Clinical features and natural history of Beckwith-Wiedemann syndrome: presentation of 74 new cases. Clin Genet. 1994; 46:168-74. [PubMed: 7820926]

57. Junien C. Beckwith-Wiedemann syndrome, tumourignesis and imprinting. Curr Opin Genet Dev. 1992; 2:431-8. [PubMed: 1504618]

58. Weksberg R, Smith AC, Squire J, Sadowski P. Beckwith-Wiedemann syndrome demonstrates a role for epigenetic control of normal development. Hum Mol Genet. 2003; 12 (Spec 1):R61-8. [PubMed: 12668598]

59. Weksberg R, Shuman C, Smith AC. Beckwith-Wiedemann Syndrome. Am J Med Genet C Semin Med Genet. 2005; 137:12-23. [PubMed: 16010676]

60. Clayton-Smith J, Read AP, Donnai D. Monozygotic twinning and Weidemann-Beckwith syndrome. Am J Med Genet. 1992; 42:633-7. [PubMed: 1609846]

61. Weksberg R, Shuman C, Caluseriu O, Smith AC, Fei YL, Nishikawa J, et al. Discordant KCNQ1OT1 imprinting in sets of monozygotic twins discordant for Beckwith-Wiedemann syndrome. Hum Mol Genet. 2002; 11:1317-25. [PubMed: 12019213]

62. DeBaun MR, Niemitz EL, Feinberg AP. Association of in vitro fertilization with BeckwithWiedemann syndrome and epigenetic alteration of LIT1 and H19. Am J Hum Genet. 2003; 72:156-60. [PubMed: 12439823]

63. Maher ER, Brueton LA, Bowdin SC, Luharia A, Cooper W, Cole TR, et al. Beckwith-Wiedemann syndrome and assisted reproductive technology (ART). J Med Genet. 2003; 40:62-4. [PubMed: 12525545]

64. Gicquel C, Gaston V, Mandelbaum J, Siffroi JP, Flahault A, Le Bouc Y. In vitro fertilization may increase the risk of Beckwith-Weidemann syndrome related to the abnormal imprinting of the KCNQ1OT gene. Am J Hum Genet. 2003; 72:1338-41. [PubMed: 12772698]

65. Halliday J, Oke K, Breheny S, Algar E, Amor DJ. Beckwith-Weidemann syndrome and IVF: a case-control study. Am J Hum Genet. 2004; 75:526-8. [PubMed: 15284956]

66. Chang AS, Moley KH, Wangler M, Feinberg AP, DeBaun MR. Association between BeckwithWiedemann syndrome and assisted reproductive technology: a case series of 19 patients. Fertil Steril. 2005; 83:349-54. [PubMed: 15705373]

67. Sutcliffe AG, Peters CJ, Bowdin S, Temple K, Reardon W, Wilson L, et al. Assisted reproductive therapies and imprinting disorders - a preliminary British survey. Hum Reprod. 2006; 21:100911. [PubMed: 16361294]

68. Lidegaard O, Pinborg A, Andersen AN. Imprinting diseases and IVF: Danish National IVF cohort study. Hum Reprod. 2005; 20:950-4. [PubMed: 15665017]

69. Kallen B, Finnstrom O, Nygren KG, Olausson PO. In vitro fertilization (IVF) in Sweden: risk for congenital malformations after different IVF methods. Birth Defects Res A Clin Mol Teratol. 2005; 73:162-9. [PubMed: 15678490]

70. Bowdin S, Allen C, Kirby G, Brueton L, Afnan M, Barratt C, et al. A survey of assisted reproductive technology births and imprinting disorders. Hum Reprod. 2007; 22:3237-40. [PubMed: 17921133]

71. Doornbos ME, Maas SM, McDonnell J, Vermeiden JPW, Hennekam RCM. Infertility, assisted reproduction technologies and imprinting disturbances: a Dutch study. Hum Reprod. 2007; 22:2476-80. [PubMed: 17586835]

72. Kishino T, Lalande M, Wagstaff J. UBE3A/E6-AP mutations cause Angelman syndrome. Nat Genet. 1997; 15:70-3. [PubMed: 8988171]

73. Mann MR, Bartolomei MS. Towards a molecular understanding of Prader-Willi and Angelman syndromes. Hum Mol Genet. 1999; 8:1867-73. [PubMed: 10469839]

74. Steffenburg S, Gillberg CL, Steffenburg U, Kyllerman M. Autism in Angelman syndrome: a population-based study. Pediatr Neurol. 1996; 14:131-6. [PubMed: 8703225] 
75. Orstavik KH, Eiklid K, Van Der Hagen CB, Spetalen S, Kierulf K, Skjeldal O, et al. Another case of imprinting defect in a girl with Angelman syndrome who was conceived by intracytoplasmic sperm injection. Am J Hum Genet. 2003; 72:218-9. [PubMed: 12549484]

76. Ludwig M, Katalinic A, Gross S, Sutcliffe A, Varon R, Horsthemke B. Increased prevalence of imprinting defects in patients with Angelman syndrome born to subfertile couples. J Med Genet. 2005; 42:289-91. [PubMed: 15805153]

77. Manning M, Lissens W, Bonduelle M, Camus M, De Rijcke M, Liebaers I, et al. Study of DNAmethylation patterns at chromosome 15q11-q13 in children born after ICSI reveals no imprinting defects. Mol Hum Reprod. 2000; 6:1049-53. [PubMed: 11044469]

78. Moll AC, Kuik DJ, Bouter LM, Den Otter W, Bezemer PD, Koten JW, et al. Incidence and survival of retinoblastoma in the Netherlands: a register-based study 1862-1995. Br J Ophthalmol. 1997; 81:559-62. [PubMed: 9290369]

79. Greger V, Passarge E, Hopping W, Messmer E, Horsthemke B. Epigenetic changes may contribute to the formation and spontaneous regression of retinoblastoma. Hum Genet. 1989; 83:155-8. [PubMed: 2550354]

80. Ohtani-Fujita N, Dryja TP, Rapaport JM, Fujita T, Matsumura S, Ozasa K, et al. Hypermethylation in the retinoblastoma gene is associated with unilateral, sporadic retinoblastoma. Cancer Genet Cytogenet. 1997; 98:43-9. [PubMed: 9309117]

81. Moll AC, Imhof SM, Cruysberg JRM, Schouten-van Meeteren AY, Boers M, van Leeuwen FE. Incidence of retinoblastoma in children born after in-vitro fertilization. Lancet. 2003; 361:309-10. [PubMed: 12559867] 


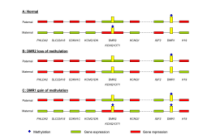

Figure 1.

Diagram showing epigenetic alteration of imprinted gene cluster at chromosome $11 \mathrm{p} 15.5 \mathrm{in}$ BWS. A: normal, B: BWS caused by DMR2 loss of methylation (most common etiology of BWS in children born after ART), C: BWS caused by DMR1 gain of methylation. 


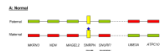



Figure 2.

Diagram showing epigenetic alteration of imprinted gene cluster at chromosome 15q11-13

in AS. A: normal, B: AS caused by SNRPN DMR loss of methylation. 
Table 1

Human phenotypes associated with imprinted genes (10).

\begin{tabular}{|l|l|}
\hline Syndrome & Chromosome location \\
\hline$\square$ Beckwith-Wiedemann syndrome & $11 \mathrm{p} 15$ \\
$\square$ Prader-Willi syndrome & $15 \mathrm{q} 11-\mathrm{q} 12$ \\
$\square$ Angelman syndrome & $15 \mathrm{q} 11-\mathrm{q} 12$ \\
$\square$ Silver-Russell syndrome & $7 \mathrm{p} 11-\mathrm{p} 13,7 \mathrm{q} 31$-qter \\
$\square$ Transient neonatal diabetes mellitus & $6 \mathrm{q} 24$ \\
$\square$ PHP1b, Albright hereditary osteodystrophy, McCune-Albright syndrome & $20 \mathrm{q} 13$ \\
$\square$ Familial nonchromaffin paraganglioma & $11 \mathrm{q} 13$ \\
$\square$ Maternal and paternal UPD14 syndromes & 14 \\
\hline
\end{tabular}


Table 2

Molecular basis of Beckwith-Wiedemann syndrome (59).

\begin{tabular}{|l|l|}
\hline Molecular subgroup & Approximate percentage \\
\hline Epigenetic error on chromosome 11p15 & \\
Loss of methylation at DMR 2 (KvDMR1 located within KCNQ1 gene) & $50 \%$ \\
Gain of methylation of DMR1 & $2-7 \%$ \\
\hline Paternal uniparental disomy & $20 \%$ \\
\hline Chromosomal alterations & $<1 \%$ \\
Paternal duplication & $<1 \%$ \\
\hline Chromosome 11 inversions and translocation & $10 \%$ \\
\hline Mutation in the gene CDKNIC & $10 \%$ \\
\hline Unknown etiology & \\
\hline
\end{tabular}






Fertil Steril. Author manuscript; available in PMC 2011 April 25. 


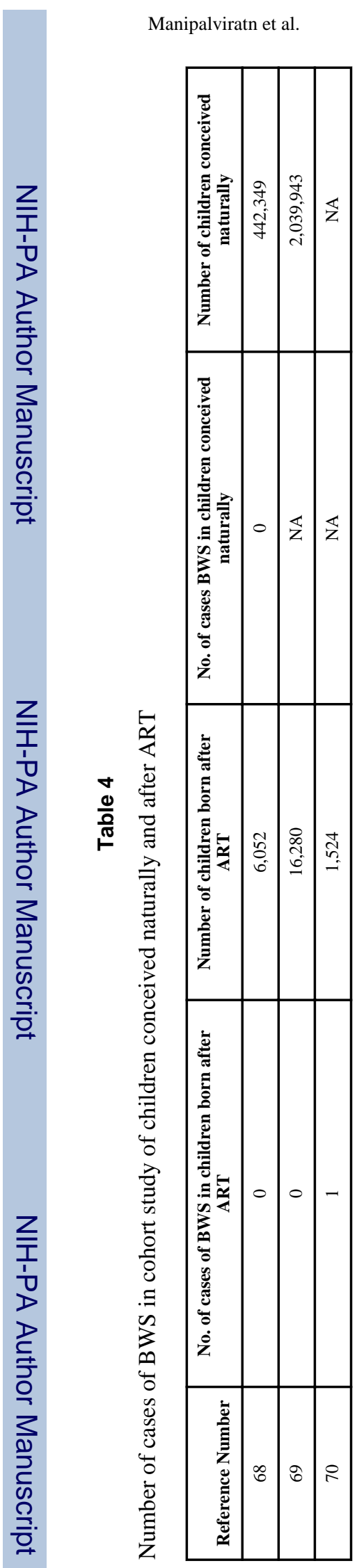

Fertil Steril. Author manuscript; available in PMC 2011 April 25. 
Table 5

Number of cases of AS conceived after IVF/ICSI

\begin{tabular}{|c|c|c|c|}
\hline Reference Number & Type of study & $\begin{array}{c}\text { No. of case(s) of AS in children born after } \\
\text { ART }\end{array}$ & $\begin{array}{c}\text { No. of case(s) having imprinting defect as a } \\
\text { cause }\end{array}$ \\
\hline 1 & Case series & 2 ICSI & $2(100 \%)$ \\
\hline 75 & Case report & 1 ICSI & $1(100 \%)$ \\
\hline 76 & Survey & 3 ICSI & $1(33.3 \%)$ \\
\hline 67 & Survey & 1 IVF & $1(100 \%)$ \\
\hline
\end{tabular}

